\title{
Aplicando a metodologia S - IVAC em escolas para explorar a criatividade dos alunos em resolver problemas de saúde sexual
}

\author{
Teresa Vilaça \\ Departamento de Metodologia da Educação, \\ Instituto de Educação e Psicologia, Universidade do Minho, Braga, Portugal \\ tvilaca@iep.uminho.pt \\ Bjarne Bruun Jensen \\ Centro de Pesquisa para Educação Ambiental e da Saúde, \\ The Danish University of Education, Copenhagen \\ bjbj@dpu.dk
}

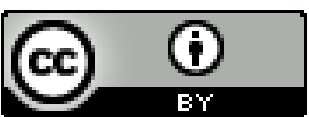

Educação: teoria e prática, Rio Claro, SP, Brasil - elSSN: 1981-8106

Está licenciada sob Licença Creative Common

Publicado pela primeira vez em Inglês em Vilaça, T. \& Jensen, B. B.(2010). Applying the S-IVAC methodology in schools to explore students'creativity to solve sexual health problems. In M. MONTANÉ \& J. SALAZAR (Ed.), ATEE 2009 Annual Conference Proceedings (pp. 215-227). Brussels, Belgium: Association for Teacher Education in Europe.

VILAÇA, T. \& JENSEN, B. B. (2009). Applying the S - IVAC methodology in schools to explore students' creativity to solve sexual health problems. Trabalho apresentado no $34 a$ Conferência Annual da Associação para Educação de Professores na Europa. Palma de Mallorca, 29 de Agosto - 2 de Seembro de 2009. Espanha: Universidade de Palma de Mallorca (no prelo).

\section{Resumo}

Uma pesquisa para avaliar o desenvolvimento participativo e ações orientadas para projetos de educação sexual em escolas (do 7ㅇ ao 12ㅇan anos) ( $n=16)$, com o uso de TIC descreverá os seguintes objetivos: i) discutir a criatividade da visão dos alunos em relação a como o mundo e suas vidas poderiam ser, e como a sociedade e meio ambiente poderiam melhorar em relação a suas preocupações sexuais; e ii) caracterizar o tipo de ações feitas para resolver seus problemas sexuais. A observação do participante, entrevista em grupo e materiais disponibilizados online pelos alunos foram selecionados como técnicas de pesquisa para triangulação dos dados. Os resultados principais mostraram que esses alunos pensaram de forma criativa para formular visões e desenvolver, individualmente, ações reflexivas que levam a mudanças positivas em seus estilos de vida e/ou condições de vida que melhoram sua sexualidade.

Palavras chaves: Sexualidade; educação; conhecimento orientado para ação; competência ação. 


\title{
Applying the S - IVAC methodology in schools to explore students' creativity to solve sexual health problems
}

\begin{abstract}
A research to evaluate the development of participatory and action-oriented sexuality education projects in schools ( $7^{\text {Th }}$ to $12^{\text {th }}$ grades) $(n=16)$, with the use of ICT will be described with the following objectives: i) to discuss the creativity of students' visions regarding how the world and their lives could be, and how society and the environment could be improved in relationship to their particular sexual concerns; and ii) to characterize the type of actions carried out to solve their sexual problems. Participant observation, group interviews and materials put online by students were selected as research techniques for the triangulation of data. The principal results showed that these students thought creatively to formulate visions and develop, individually or collectively, reflexive actions, which lead to positive changes in their lifestyles, and/or living conditions, which improve their sexuality.
\end{abstract}

Key Words: Sexuality education; action-oriented knowledge; visions; actions; action competence.

\section{Aplicando la metodología S - IVAC en las escuelas para explorar la creatividad de los alumnos en resolver problemas de salud sexual}

\begin{abstract}
Resumen
Una investigación para evaluar el desarrollo participativo y acciones orientadas a proyectos de educación sexual en las escuelas (del 70 al 12 años) ( $n=16)$, con el uso de TIC describirá los siguientes objetivos: i) discutir la creatividad de la visión de los alumnos con relación a cómo el mundo y sus vidas podrían ser, y cómo la sociedad y medio ambiente podrían mejorar con relación a sus preocupaciones sexuales; y ii) caracterizar el tipo de acciones llevadas a cabo para resolver sus problemas sexuales. Los alumnos seleccionaron la observación del participante, entrevista en grupo y materiales disponibilizados en línea como técnicas de investigación para la triangulación de los datos. Los resultados principales mostraron que esos alumnos pensaron de forma creativa para formular visiones $y$ desarrollar, individualmente, acciones reflexivas que llevan a cambios positivos en sus estilos de vida y/o condiciones de vida que mejoran su sexualidad.

Palabras clave: Sexualidad. Educación. Conocimiento orientado para la acción. Competencia acción.
\end{abstract}

\section{Introdução}

\section{O contexto português da educação sexual na comunidade escolar}

A abordagem para a educação sexual adotada em Portugal tem sido focada em aspectos da saúde sexual associados com a aquisição de resultados de saúde que são 
geralmente vistos como positivos (por exemplo: respeito a si e aos outros, auto estima, relações humanas compensatórias, relações sexuais prazerosas e desejo maternal/paternal), e a fuga de resultados negativos (por exemplo: gravidez indesejada, doenças sexualmente transmissíveis/ infecção por HIV, coerção sexual). A atual legislação portuguesa defende a inclusão compulsória da educação sexual nas escolas primárias, secundárias e cursos preparatórios, dentro de um programa que objetiva a promoção da saúde e sexualidade humana, onde serão dadas informações adequadas sobre sexualidade humana, sistema reprodutivo e a psicologia da reprodução, AIDS e outras doenças sexualmente transmitidas, métodos anticoncepcionais e planejamento familiar, relações interpessoais, responsabilidade partilhada e igualdade de gêneros. Esta área de treinamento estudantil global deve ser integrada ao plano de aula. O modelo de currículo dominante declarou que a transdisciplinaridade deve ser desenvolvida através da integração das disciplinas curriculares e na forma interdisciplinar no Projeto e Áreas de treinamento civil (áreas não disciplinas). 0 quadro normativo reforça o papel da família na educação sexual na comunidade escolar, o papel dos professores no desenvolvimento de projetos escolares e no desenvolvimento de coparceiras, e o papel dos alunos como atores genuínos e participantes ativos na seleção dos problemas e na resolução de problemas individuais e coletivos relacionados s saúde sexual e reprodutiva.

Em agosto de 2009, a Assembleia da República Portuguesa publicou a lei final sobre educação sexual nas escolas (Lei n.o 60/2009 de 6 de Agosto), que estabelece como aplicar educação sexual compulsória na comunidade escolar no ano seguinte (2009/2010). O governo exigiu a integração da educação sexual no âmbito da Educação de Saúde na área curricular de não disciplinas em escolas primárias e preparatórias (dos 6 aos 14 anos de idade) e em disciplinas e áreas curriculares de não disciplinas nas escolas secundárias (dos 15 aos 17 anos de idade) de modos pré determinados (artigo 3), e com conteúdo curricular dirigido (artigo 4) que serão definidos pelo governo Português em breve. Foi definido um mínimo de 6 horas para desenvolver educação sexual da 1a à 6a série (dos 6 aos 11 anos de idade) e um mínimo 12 horas da 7ạ à 12a série, distribuídas de forma balanceada entre os três períodos do ano escolar (artigo 5).

Essa lei também estabeleceu que a educação sexual será compulsória em Projetos Escolares Educativos, como planejado pelo Conselho Geral, depois de ouvida a Associação de 
Alunos, Associação de Pais e Mestres (artigo 6) e em Projetos de Classe onde os conteúdos e temas serão desenvolvidos pela classe assim como as iniciativas e visitas e organizações externas, técnicos e especialistas envolvidos no Projeto serão definidos (artigo 7). 0 treinamento necessário do professor coordenador de educação sexual e de saúde, o professor responsável pelo Projeto de Classe em Educação Sexual e de Saúde e outros professores envolvidos também foi estabelecido pelo Ministério da Educação (artigo 8). Simultaneamente, de acordo com o artigo 10, até o início do ano escolar 2010-2011, um Escritório de apoio e Informação ao aluno no âmbito de educação de saúde e sexualidade funcionará pelo menos uma manhã ou tarde por semana com profissionais treinados nestas áreas. Esse Escritório articula suas atividades com o Centro de Saúde local ou outras organizações públicas, como o Instituto do Jovem Português e deve garantir um espaço com Internet que dê ao aluno informação e respostas rápidas à suas dúvidas ou questões. Esse Escritório deve ser organizado com a participação estudantil, garantindo confidencialidade a eles, ser integrado a projetos educativos envolvendo alunos no estabelecimento de objetivos e, com a colaboração do Centro de Saúde, prover aos alunos acesso adequado a métodos anticoncepcionais.

Pais, alunos e representantes da comunidade local devem ter um papel ativo no desenvolvimento desses projetos e devem ser informados sobre todas as atividade curriculares e não curriculares desenvolvidas na área da educação de sexualidade (artigo 11). O Ministério da Saúde garante condições necessárias para que as Unidades de Saúde cooperem com as escolas e seus estabelecimento de protocolos com Organizações Não Governamentais reconhecidas especializadas em educação de sexualidade para desenvolver projetos específicos em formato a ser definido pelo governo (artigo 9). O Ministério da Educação deve também garantir a avaliação desses projetos escolares a elaboração de relatórios de avaliação (artigo 13)

A lei acima mencionada foi precedida por debate público pela sociedade civil organizada. Naquela ocasião, muitas opiniões contraditórias emergiram na opinião pública, por exemplo em relação à proporção.

O Diretor Executivo da Associação para o Planejamento Familiar (...) considera que "é importante facilitar o máximo possível, o acesso a métodos anticoncepcionais para jovens que são sexualmente ativos". Por outro lado (...) o Presidente da Confederação [Nacional] de 
Pais (...) defende que pais "entendem que a disponibilidade de preservativos pode ser realizada usando uma lógica diferente. Até os 14 anos de idade, todos os problemas relacionados com educação sexual devem profundamente envolver as famílias (...) \{e\} somente aos 16, as escolas deveriam dirigir os alunos aos Centros de Saúde (...) [porque os preservativos] não podem ser disponibilizados em escolas, como se fossem qualquer outro tipo de bens de consumo" (...) O Coordenador da Comissão Nacional Contra HIV - AIDS, "a presença dos preservativos pelo menos dá a possibilidade de minimizar os riscos. Sabemos que uma grande proporção das crianças tem relações sexuais antes dos 15 anos de idade (...) e temos um índice inaceitável de gravidez na adolescência (...) [e] a distribuição de preservativos não é um incentivo à sexualidade ou promiscuidade, mas uma garantia de prevenir infecções [sexualmente transmitidas" (TSF, 2009-05-18)

O Presidente da Conferência Episcopal Portuguesa (...) considera que este é um assunto sensível que foi legislado de forma precipitada. (...) [Ele] defende a Educação Sexual, mas com regras mais fechadas, porque, em sua opinião, a lei só convida os jovens a desenvolver determinadas experiências: O que importa é a humanização da sexualidade que é integrada não somente em educação informativa, que pode agir como um convite à propostas [sexuais], mas em uma educação mais global”. (TSF, 2009-05-14)

O debate público continua até agora. As pedras fundamentais desse discurso são essencialmente: os papeis da família e da escola na educação da sexualidade juvenil; a disponibilidade ou não de métodos contraceptivos, como preservativos, pílulas anticoncepcionais e do dia seguinte nas escolas; o referencial ético para educação de sexualidade nas comunidades escolares de ONGs das quais as escolas põem adotar como coparceiros em seus projetos educativos; e a falta ou deficiência de preparo científico, pedagógico e ético de professores e outros funcionários da escola. Parte dessa discussão de não aceitar a educação de sexualidade como previsto nas políticas nacionais esta, provavelmente, ligada à falta de conhecimento relacionado à reformas recentes (Lei de Bases do Sistema Educativo, Lei $\mathrm{n} \cong$ 49/2005, de 30 de Agosto), particularmente a constituição e o papel do Quadro Escolar (artigo 48ํㅡ, no4) ou uma vulnerabilidade visível da comunidade local para implementar esse recente modelo de novo gerenciamento de forma participativa e democrática. 


\section{Conhecimento orientado para ação, criatividade, comunicação e participação}

Problemas de saúde atuais são um grande desafio para a educação. Se as possíveis soluções para esses problemas estiverem sendo desenvolvidas, é necessário uma ruptura fundamental com o modo presente de pensar em saúde. No mundo educacional isto significa saber ser as questões de conteúdos de aprendizagem central deveriam ter uma posição mais central do que questões de natureza metodológica. Uma consequência importante é que a educação de saúde deve lidar com um contexto interdisciplinar orientado aos problemas. As Ciências Naturais podem descrever a extensão do problema de saúde; As Humanidades podem ser planejadas dentro do trabalho, considerando as mudanças desejáveis na sociedade futura e a Ciências Sociais podem ser usadas na conexão com a elucidação de todo o espectro de possibilidades de ação (coletivas e individuais) que põem ser encontradas numa sociedade democrática (Jensen, 1994; 1995; 2000).

O ensino orientado para ação, dentro de uma perspectiva democrática, envolve trabalho em uma amplo campo de conhecimento, não somente em relação às consequências de problemas de saúde, mas também, de suas causas, suas visões em relação ao futuro e o conhecimento em relação a estratégias para encontrar soluções. Ou seja, conhecimento orientado para ação é um entendimento interdisciplinar complexo construído em um processo compartilhado de diálogo crítico, reflexão, desenvolvimento de visões, planejamento e ação incluída no processo de ensino e aprendizagem (JENSEN, 2000; SIMOVSKA \& JENSEN, 2003; VILAÇA \& JENSEN, 2009). A metodologia S - IV\&M (Seleção do Problema - Investigação, Visão \& Mudança) tem sido desenvolvido como instrumento prático que pode ser usado nas escolas para estruturar a saúde promovendo atividades e tornar a participação do aluno mais fácil, com o objetivo de construir seu próprio conhecimento orientado para ação e promover o desenvolvimento de ações par aumentar a competência de ação. Este instrumento assume tais perspectivas para o que pode tratado em um projeto ou metodologia de ensino dentro da educação de saúde e de sexualidade (JENSEN, 1997; SIMOVSKA \& JENSEN, 2003; VILAÇA, 2006; 2007; 2008). Portanto, com esse modelo é possível esclarecer que tipos de insights os professores e materiais de ensino devem fornecer. Dado que o conhecimento entre as pessoas integram os elementos científicos, sociais e históricos e que os alunos alcançam esses insights melhor, se eles 
podem ganhar experiência por si próprios com as perguntas ao trabalhar nos projetos, o papel dos professores consiste, a grosso modo, em ser um consultor aos projetos orientados para ação dos alunos, ao invés de somente enchê-los com fatos científicos pesados.

Uma perspectiva interdisciplinar pode ser considerada como uma pré condição no desenvolvimento da competência de ação. Uma abordagem de educação de saúde, aqui delimitada implica em não poder ser meramente tratada dentro de uma disciplina das Ciências Naturais. Se somente os aspectos científicos forem aplicados, o foco será descrever - e ilustrar - os efeitos que problemas sérios apresentam e como resultado o ensino produzido será preocupação dos alunos e a falta de poder deles para resolver o problema. Se a falta de poder for transformada ou qualificada em habilidade real para agir, as aulas devem colocar no centro a perspectiva da ação e envolver as perspectivas sociais na discussão de soluções para seus problemas de saúde (JENSEN, 1995; SIMOVSKA \& JENSEN, 2003). Baseado na experiência de um grande número de grupos de estudo - dentro do projeto de Escolas que promovem Saúde e outras conexões no que concerne a área de educação ambiental - as oito perspectivas abaixo mencionadas podem ser tratadas em projetos dentro da área de saúde (figura1).
1. Em qual disciplina deve ser trabalhado?
2. Com que problema dentro da disciplina em questão devemos trabalhar?
3. Quais são as causas do problema?
4. Por que se tornou um problema?
5. Que alternativas pode-se imaginar?
6. Que planos e ação existem para obter essas alternativas?
7. Que barreiras serão trazidas à tona através dessas ações?
8. Que ações serão iniciadas?

Figura 1. As perspectivas dentro de projetos de educação de saúde (Jensen, 1994, p. 83)

Essas perspectivas não necessariamente representam passos que devam ser trabalhados seguindo uma determinada ordem, mas questões que devem ser tratadas durante o processo de aprendizagem. Lidar com essas perspectivas significa criar algumas 
precondições importantes para desenvolver competência de ação em educação de saúde (e sexualidade) (Jensen, 1994). Jensen (2000) argumenta que o objetivo principal em educação saúde (e sexualidade) devem ser o desenvolvimento da habilidade dos alunos de agir e mudar, portanto, é possível concluir que o conhecimento e insights devam ser, em essência, orientados para ação. Este ponto de partida tem grandes consequências no tipo de conhecimento que serão foco do planejamento, implementação e avaliação do processo de ensino e aprendizagem (Vilaça, 2006).

Esse tipo de conhecimento, especialmente, quando é o único conhecimento que os alunos possuem, não promove ações e, consequentemente não promove empoderamento do aluno e competência de ação. É necessário insistir na inclusão de análise causal e nas maneiras de produzir mudanças na educação de saúde e sexualidade (Jensen, 2000).

O quadro teórico mencionado foi aplicado num projeto de educação para sexualidade orientado para ação e participativo, usando tecnologia e informação e comunicação (TIC). Os resultados deste Projeto será descrito com os seguintes objetivos: i) discutir a criatividade das visões dos alunos em relação a como, de um modo geral, o mundo e suas vidas poderiam ser e como a sociedade e o meio ambiente poderiam melhorar em relação a suas preocupações sexuais; e ii) caracterizar o tipo de ações feitas para resolver seus problemas sexuais.

\section{Metodologia}

\subsection{Amostra}

Oitocentos e dezessete alunos das 7a à 12a séries, de 16 escolas do distrito de Braga, no norte de Portugal, se envolveram nesse projeto de educação de sexualidade e constituíram a população online para esta pesquisa. Cada ano escolar em educação preparatória tinha aproximadamente o mesmo número de alunos no projeto $(27,2 \%, 27,3 \%$ e $26,2 \%$ das $7 \underline{a}$, $8 \underline{a}$ e $9 \underline{a}$ séries respectivamente). O mesmo não ocorre no ensino médio (10,0\% e 9,3\% nas $10^{\mathrm{a}}$ e $11^{\text {a }}$ séries respectivamente). Em todas as séries, a participação feminina foi predominante, exceto na $7 \underline{a}$ série.

A fim de permitir uma compreensão mais profunda da implementação do projeto, seis escolas envolvendo 350 alunos desse projeto foram selecionados da população inicial, 
para investigar como a metodologia de educação de sexualidade foi implementada na Área do Projeto no ensino médio (10ạ a 12ạ séries) e na Área do Projeto e/ou Treinamento Cívico no Ciclo preparatório ( $7^{\text {a. }}$ a $9^{\text {a }}$ séries).

\subsection{Métodos e técnicas de coleta e análise de dados}

Usamos técnicas de pesquisa, observação participativa, entrevista em grupos semiestruturados, matérias do projeto disponibilizados online pelos alunos, diários de classe online e fórum de discussão a distância. Os alunos, com a colaboração de professores, concordaram com o método de investigação focado neles. Foi feita uma triangulação destas técnicas e as interferências ou conclusões entre o pesquisador e os participantes.

Este estudo foi desenvolvido em 2 fases. Durante o primeiro ano escolar, aproximadamente 5 meses, os alunos criaram a infraestrutura online para participar no website do projeto, debateram o conceito de sexualidade e educação de sexualidade e selecionaram os temas/problemas que gostariam de discutir. Na segunda fase, que ocorreu no ano escolar seguinte, os alunos desenvolveram um ou dois temas/problemas que eles gostariam de ver discutidos no âmbito da metodologia do projeto.

No tratamento dos dados que serão apresentados e discutidos mais tarde, toda a escola foi usada como uma unidade e análise.

\section{Resultados e discussão}

Visões criativas como pré-requisitos para o desejo e habilidade para iniciar mudanças

Alunos de 50 escolas que realizaram projetos de educação de sexualidade com ações orientadas desenvolveram ideias, sonhos e percepções em relação ao seu futuro de suas vidas e da sociedade na qual eles crescerão em relação aos seguinte problemas escolhidos pelos alunos para cumprir o projeto: a prevenção de gravidez na adolescência e métodos contraceptivos (73,3\% das 15 escolas); prevenção de infecções sexualmente transmitidas (60,0\%); a primeira relação sexual $(46,7 \%)$; comportamento sexual $(40,0 \%)$; diálogo com os pais a respeito da sexualidade do adolescente (40,0\%); puberdade/despertar da maturidade sexual (33,3\%); homossexualidade (20\%); relações interpessoais e amizades (13,3\%); a Consulta ao Jovem no Centro de Saúde (13,3\%); a pílula do dia seguinte (13,3\%); fertilidade humana (6,7\%); aborto (6,7\%); amor, intimidade e comunicação entre parceiro românticos 
$(6,7 \%)$; pedofilia $(6,7 \%)$ e outras doenças psicossexuais $(6,7 \%)$; sexualidade adulta $(6,7 \%)$; e disfunções sexuais $(6,7 \%)$.

Os alunos trabalharam numa dimensão ampla e positiva dos problemas sexuais na seguintes visões que eles desenvolveram nos projetos orientados para ação.

As visões desenvolvidas "para melhorar o diálogo com os pais em relação a sexualidade" foram, nas vozes dos alunos as seguintes: "nós deveríamos ter mais coragem e iniciativa para conversar como nossos pais"; "nós devemos começar a falar com nossos pais sobre anticoncepcionais e gravidez indesejada"; "precisamos abrir nossos corações com os pais para não se sentir tão por baixo"; "os pais deveriam ter uma mente mais aberta para que a iniciativa de conversar sobre tais temas viessem deles"; "a sociedade deveria aceitar a opção sexual de cada pessoa". Estas visões foram apresentadas como uma consequência do desejo deles em mudar as causas dos problemas identificados neles próprios (por exemplo, "por que nós sentimos vergonha de expor estas questões (sexuais) até com nossos pais?"; "por que sentimos medo que nossos pais nos censurem?"; identificados em seus pais (por exemplo, "por que muitos [pais] agem de forma agressiva e até violenta?"; "por que eles pensam que estão agindo da melhor maneira ao não dizer nada?"; "eles deveriam conversar conosco, porque os pais são mais velhos e receberam uma educação diferente da nossa, tiveram uma educação mais fechada em relação a essas questões e, portanto, não nos entendem") e identificados na sociedade (exemplos: "porque vivemos em uma sociedade pré-concebida e ainda há muitos tabus, a sociedade se revela como muito moderna e receptiva m relação a sexualidade, mas nós todos sentimos na verdade não é assim").

As visões desenvolvidas "para educar colegas mais velhos em relação a sexualidade "incluiu: promover debates; realizar discussões; distribuir folhetos informativos em farmácias, ruas e escolas; pais falam om mais facilidade com seus filhos sobre o tema; e deveria haver mais informação na mídia de massa. Estas visões atingiram as causas dos problemas identificados pelos próprios alunos (por exemplo: "envergonham as pessoas quando tocam nesse tema"; "sentem vergonha em perguntar e conversar sobre certas coisas com os pais devido a reação deles"; "falta de comunicação com os pais e amigos mais velhos") pela sociedade (por exemplo: "por que eles tem a mesma informação em algumas escolas e em casa?"; por que há falta de informação em educação sexual na escola?"; "por que não há debates sobre esses temas (sexuais)?"; "por que há tanta censura sexual?"). Nas 
visões desenvolvidas para educar colegas mais velhos, a principal preocupação foi ensinar aos mais velhos a melhorar sua condição de vida e bem estar e só então colaborar na promoção da saúde sexual e reprodutiva dos colegas mais velhos.

A visão dos alunos desenvolvida "para educá-los e a seus colegas da mesma idade a fim de resolver o problema de falta de conhecimento sobre como obter e usar anticoncepcionais" foram: aumentar seu conhecimento do uso de anticoncepcionais e sua eficácia; aperfeiçoar habilidades sociais e pessoais para prevenir uma gravidez não desejada ou não pretendida; encontrar alternativas ao sexo vaginal; melhorar o acesso aos preservativos e pílulas; e aperfeiçoar o diálogo sobre estas questões com pais e professores. A intenção deles foi agir para eliminar as causas dos problemas identificados neles próprios e em seus colegas da mesma idades (exemplos: "por que não informa-los, na maioria das vezes eles nem sabem o que é planejamento familiar"; "eles são irresponsáveis ao não usar anticoncepcionais"; "eles não sabem como usar anticoncepcionais"; "quando é a primeira vez, muitos não sabem quais são e como usar os métodos contraceptivos"; "eles não conhecem bem os métodos e não sabem como usá-los"; "na ansiedade de fazer sexo eles esquecem tudo e também os anticoncepcionais"; "eles acham que sentirão menos prazer se usar preservativo"; "eles acham que não correm riscos") e as causas sociais do problema (por exemplo: "as meninas são pressionadas e para não perder seus namorados elas tem relação sexual"; "elas quase sempre vão para baladas, bebem e depois não sabem o que fazer e os meninos se aproveitam delas"; "devido a influência de más companhias, porque se sentem inferior aos colegas mais velhos que já tiveram relações sexuais"; "a liberdade que a maioria dos pais nos dá, nos faz cometer muitos erros").

As visões desenvolvidas "para se educar e a seus colegas da mesma idade na resolução de problemas em relações interpessoais" incluíram; "saber como tomar decisões sem ser influenciados"; "saber como escolher amigos, resistindo a hábitos negativos que amigos ensinam sem perder a amizade"; e "buscar um conselheiro para ajudar a resolver problemas entre amigos". Eles pensavam em como eliminar as causas de problemas individuais, como por exemplo: "é difícil dizer não a hábitos negativos, é difícil dizer não porque nós nos sentimos ameaçados pelos colegas de classe"; "não sabemos recusar vícios porque temos medo de perder um amigo e somos pressionados e imitamos"). 
Esses projetos criaram uma ponte entre a educação e a saúde sexual porque o que os alunos desejam é alcançado na comunicação interpessoal, afeição, prazer, saúde e fertilização e práticas de educação de sexualidade nos trabalhos escolares em visões positivas e amplas de sexualidade. Tais práticas objetivaram não só seus estilos de vida sexual, mas também suas condições de vida, numa perspectiva de bem estar e ausência de doença.

\section{Ação \& Mudança}

Os alunos como catalizadores de mudança das concepções e práticas de seus pais em relação a sexualidade jovem ocorreu com dois tipos de ações: entrevistas e mesas-redondas com alunos ou alunos e especialistas convidados pelos alunos (figura 2)
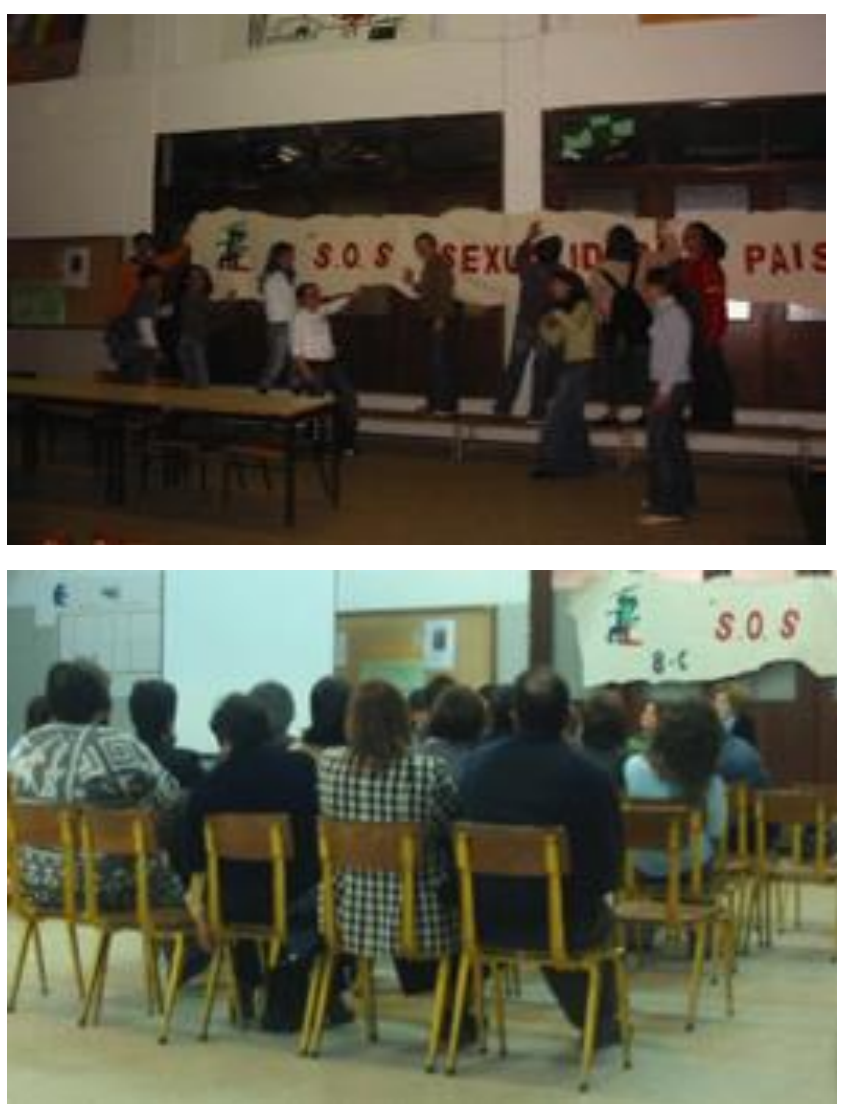

Figura 2. Ações deveriam sempre ser parte do ensino: Mesa-redonda para pais coordenado por alunos e especialistas 
Na mesa-redonda, os alunos do ensino médio explicaram aos seus pais os problemas do dia-a-dia que eles identificam como reais na idade deles relacionado à sexualidade, as razões pelas quais eles as consideravam como problemas prioritários para ajuda-los a resolver a falta de facilidade de conversar com os pais sobre sexualidade, por que era importante para eles conversar confortavelmente com os pais sobre sexualidade, por que eles não conversavam confortavelmente com os pais sobre estas questões e quais eram as consequências a curto e longo prazo para eles e para a sociedade se tais problemas não fossem resolvidos. Eles também explicaram o que gostariam que acontecesse no futuro, planejar ações dentro dessas visões e apresentar algumas atitudes e comportamentos aos jovens e pais para serem discutidos e depois assumidos por todos na forma de um contrato a ser cumprido no futuro. Quando os especialistas eram convidados, os alunos pediam que eles intervissem no debate adicionando mais informações a respeito de sexualidade juvenil. Nas mesas-redondas nas escolas preparatórias, os alunos somente apresentavam o projeto aos pais e preparavam com eles um chá da tarde e pediam que os especialistas conversassem sobre sexualidade na adolescência. Em todos os níveis escolares, o debate entre alunos, pais e especialistas teve participação de todos, sempre gerando novas visões para o futuro.

Educação de pares do mesmo nível escolar, do amis baixo ao mais alto, teve projetos orientados para ação com diferentes características: educação de colegas orientando sessões sobre tópicos de saúde sexual como 'professores monitores' (figura 3); concepção e apresentação de pôsteres, adesivos e extratos de notícias de jornal; escrita; ensaio e apresentação de peças ou filmes e catalizadores de mudança nos colegas através de entrevistas conduzidas. 

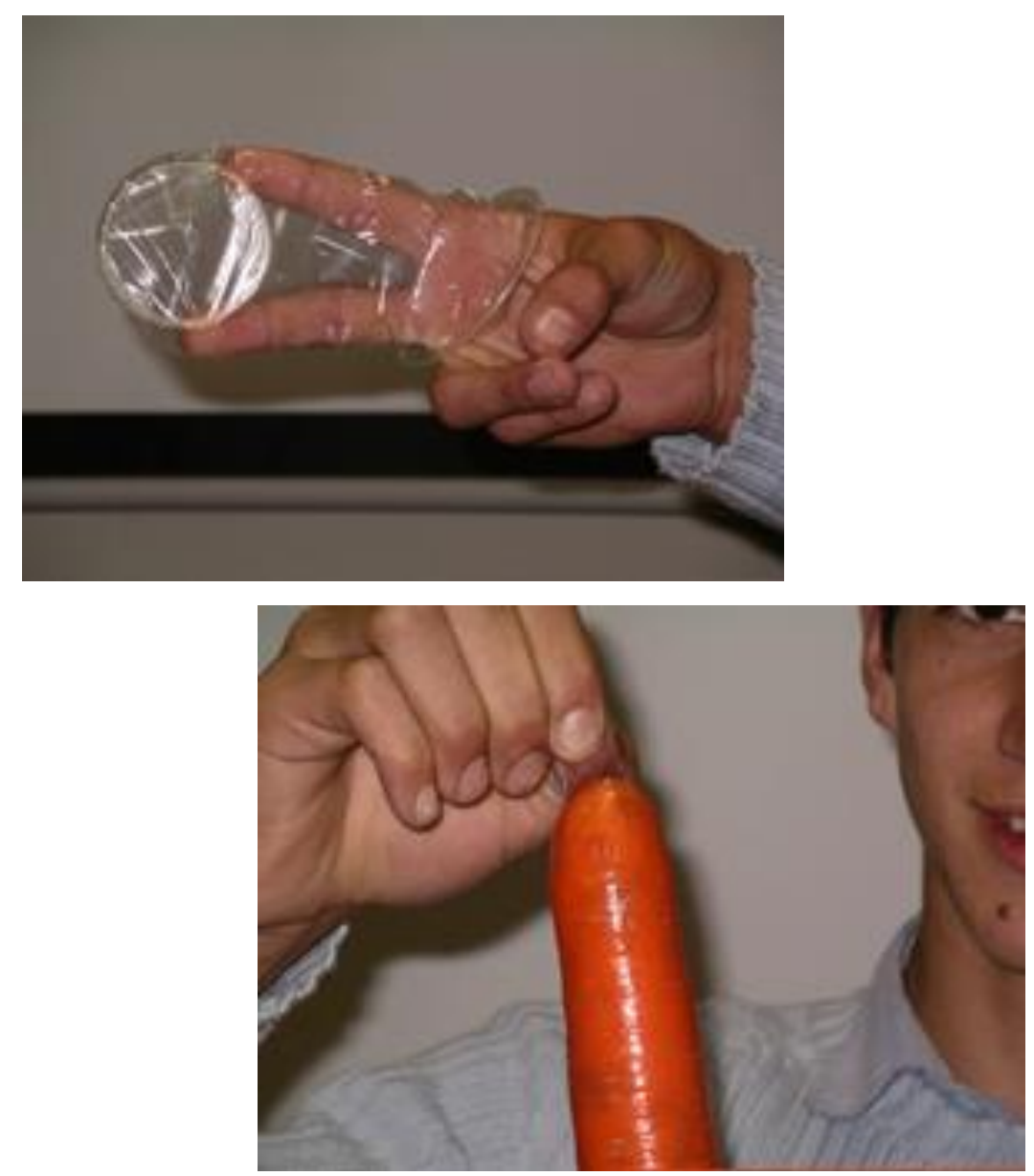

Figura 3. Ações sempre deveriam ser parte do ensino. Sessões práticas organizadas pelos alunos com a ajuda de um médico e enfermeira convidados por colegas da mesma idade.

Todas as ações em que os alunos atuaram de forma coletiva como catalizadores de mudança dos seus pais em educação de pares (de colegas mais velhos ou da mesma idade) ou em sua própria educação, trabalharam nas dimensões de uma Escola Promotora de Saúde por que: (1) as dimensões de saúde sexual trabalhadas por esses alunos mostraram uma visão de saúde ampla e holística positiva e foram criadas à partir de suas experiências pessoais e suas ideias (re) construídas de baixo para cima e numa organização contextual de amplo aprendizado; (2) os alunos foram parceiros ativos no diálogo com os pais, professores e especialistas convidados em todas as situações e fases desses projetos orientados para ações; (3) suas ações revelaram resultados de aprendizagem categorizados em um nível crítico de alfabetização em educação de saúde com a aplicação do conhecimento adquirido nas quatro áreas orientadas para ação definidas por Jensen, revelando evidências 
positivassem vários elementos constituintes da operacionalização do conceito de competência ação: insight e conhecimento, compromisso, visão e experiências ações.

\section{Conclusões e implicações}

Nesses projetos de educação de sexualidade orientados para ação e participativos, os alunos pensaram de forma criativa para encontrar soluções para mudar seus estilos e condições de vida. Eles manifestaram desejo de aumentar suas competências em conversar com seus parceiros e pais sobre sexualidade, resistir a pressões dos outros e ganhar acesso à pílulas anticoncepcionais, do dia seguinte e preservativos. Eles também manifestaram desejo em mudar hábitos de consumir álcool em baladas. Suas visões, como no conhecimento anterior orientado para ação investigado, continuaram a trabalhar o conceito de sexualidade de forma ampla e positiva; em todas as escolas os alunos deram grande ênfase no conceito de bem estar e qualidade de vida, mesmo quando o foco principal era evitar condições de saúde negativas, tais como gravidez não planejada ou indesejada e pressão dos amigos pra comportamentos não saudáveis.

Esses professores e alunos assumiram, como ponto de partida para seus trabalhos, que problemas de saúde sexual eram ancorados de forma estrutural em nossa sociedade e no nosso modo de vida e reconheceram que saúde sexual é influenciada tanto por estilos de vida (atitudes, valores e comportamentos) como por condições de vida (ambientes físicos e sociais e redes culturais e econômicas que afetam as vidas das pessoas). De um lado, eles experimentaram que as condições de vida e a sociedade afetam nossas possibilidades de ações imediatas e, por outro lado, eles perceberam que podem agir para ajudar a mudar a rede social. Assim, seus projetos contribuíram para o empoderamento e desenvolvimento da competência ação, da forma está estabelecida pela Rede Europeia de Escolas Promotoras de Saúde, e mais recentemente pelas Escolas para Saúde na Europa.

\section{Referências}

JENSEN, B. B. (1994). Action, action competence and change in the field of environmemtal and health educationlenge. In B. B. JENSEN \& K. SCHNACK (Eds.). Action and Action Competence as Key Concepts in Critical Pedagogy. Copenhagen: Didaktiske Studier, Studies 
in Educational Theory and Curriculum, Royal Danish School of Educational Studies, p.73-85.

JENSEN, B. B. (1995). Concepts and models in a democratic health education. In (Ed.). Research in environmental and health education. Copenhagen: Research Centre for Environmental and Health Education. The Danish University of Education, p.151-169.

JENSEN, B. B. (1997). A case of two paradigms within health education. Health Education Research, 12 (4) p.419-428.

JENSEN, B. B. (2000). Participation, commitment and knowledge as components of pupil's action competence. In B. B. JENSEN, K. SCHNACK \& V. SIMOVSKA (Eds.). Critical Environmental and Health Education. Research Issues and Challenges. Copenhagen: Research Centre for Environmental and Health Education. The Danish University of Education, p.219-237.

SIMOVSKA V. \& JENSEN, B. B. (2003). Young-minds.net/lessons learnt: Student participation, action and cross-cultural collaboration in a virtual classroom. Copenhagen: Danish University of Education Press.

VILAÇA, M. T. (2006). Acção e competência de acção em educação sexual: uma investigação com professores e alunos do 3ำ ciclo do ensino básico e do ensino secundário. Dissertação de Doutoramento (não publicada), Universidade do Minho.

VILAÇA, T. \& JENSEN, B. B. (2009). Potentials of Action-Oriented Sex Education Projects in the Development of Action Competence. In G. BUIJS; A. JOCIUTE்; P. PAULUS; V. SIMOVSKA (Eds.). Better Schools Through Health: Learning from Practice. Case studies of practice presented during the third European Conference on Health Promoting Schools, held in Vilnius, Lithuania, 15-17 June 2009. Vilnius, Lithuania: Netherlands Institute for Health Promotion NIGZ, State Environmental Health Centre of Lithuania, pp.89-91.

VILAÇA, T. (2007). Eficácia do paradigma democrático de educação para a saúde no 
desenvolvimento da acção e competência de acção dos adolescentes em educação sexual. In BARCA, A., PERALBO, M., PORTO, A., DUARTE DA SilVA, B. E ALMEIDA, L. (eds.). Libro de Actas IX Congreso Internacional Galego-Portugués de Psicopedagoxía, Coruña: Universidade da Coruña p. 971-982.

VILAÇA, T. (2008a). Projecto de educação sexual orientado para a aç̧ão e participação: efeito nas escolas, professores, pais e alunos. In F. CRUZ, (org.). Actas do III Congresso Internacional Saúde, Cultura e Sociedade, Bragança: Associação para a Investigação e Desenvolvimento Sócio-Cultural, p. 128-159.

VILAÇA, T. (2008). Development Dynamics of Action-Oriented Learning on Health Education. In M. MARIO, I. JELÍNEK, F. FERREIRA (coord.). Proceedings of the International Association For The Scientific Knowledge International Conference: Teaching and Learning 2008, Aveiro: University of Aveiro, p. 74-83.

Enviado em Outubro/2013 